DOI: https//doi.org/10.13037/ci.vol22n49.7144

\title{
Trajetórias, objetos e concepções: jormalismo e inovação em 20 anos de pesquisa na Compós ${ }^{1}$
}

Pathways, objects and conceptions: 20 years of journalism and innovation research at Compós

Elaide Martins $^{a}$

ORCID: https://orcid.org/0000-0001-7723-7055

Maíra Evangelista de Sousa ${ }^{b}$

ORCID: http://orcid.org/0000-0002-5149-7518

Recebido em: 15/07/2020. Aprovado em: 15/12/2020.

Resumo

O objetivo deste artigo é compreender as trajetórias, objetos e concepções atribuídas ao conceito de inovação em pesquisas de Jornalismo, a fim de entender os sentidos da inovação no Jornalismo. Para tanto, analisa-se os trabalhos do GT Estudos de Jornalismo da Compós, apresentados nos últimos vinte $\operatorname{anos}(2000$ a 2019). À luz da Análise de Conteúdo, a investigação combina técnicas quantitativas e qualitativas para examinar o corpus formado por 59 artigos, selecionados de um conjunto de 200 trabalhos. Dentre seus resultados, aponta para diferentes sentidos desse conceito, associados à temporalidade, empreendedorismo e tecnologia.

Palavras-Chave: Jornalismo. Inovação. Pesquisa em Jornalismo.

\begin{abstract}
The objective of this article is to understand the pathways, objects and conceptions attributed to the Innovation concept in Journalism research, so as to understand its meanings to the field. To this end, we've analyzed the last 20 years (2000 - 2019) papers published in the Compós congress annals, specifically from the "GT Estudos de Jornalismo". Under the terms of the Content Analysis, the investigation combines quantitative and qualitative techniques to examine a corpus consisting of 59 articles selected from a set of 200 papers. The results indicate different meanings of the Innovation concept, associated with temporality, entrepreneurship and technology.
\end{abstract}

Keywords: Journalism. Innovation. Journalism research.

\section{Introdução}

Esta pesquisa tem o objetivo de compreender as trajetórias, objetos e concepções atribuídas ao conceito de inovação em pesquisas de jornalismo, a fim de entender os sentidos da inovação no jornalismo. Enfocamos nas investigações do Grupo de Trabalho (GT) Estudos

\footnotetext{
${ }^{1}$ Pesquisa financiada pela Coordenação de Aperfeiçoamento de Pessoal de Nível Superior (CAPES) via bolsa de Pós-Doutorado.

${ }^{a}$ Universidade Federal do Pará (UFPA). Pará/Brasil. E-mail: elaidemartins@gmail.com

${ }^{\mathrm{b}}$ Universidade da Amazônia (UNAMA). Pará/Brasil. E-mail: maira.evangelistadesousa@gmail.com
} 
de Jornalismo da Associação Nacional dos Programas de Pós-Graduação em Comunicação (Compós) realizadas nos últimos 20 anos, recuperando o percurso histórico do debate sobre o conceito de inovação associado ao Jornalismo. Vamos nos deter ao conjunto de trabalhos apresentados nesse GT no período de 2000 a 2019, um corpus formado por 59 artigos, resultantes de um mapeamento de 200 trabalhos.

Esse levantamento foi realizado nos anais eletrônicos da Compós ${ }^{2}$, que reúnem todos os trabalhos apresentados desde o ano 2000. Especificamente sobre o GT Estudos de Jornalismo, nos detivemos às discussões sobre inovação, partindo desse mapeamento em seus anais e selecionando os trabalhos que remetem à temática. Como critério em relação à amostragem, restringimos a seleção a artigos que fazem referências explícitas ao termo inovação e as suas variantes semânticas - mesmo reconhecendo a importância de considerar eventuais abordagens inovadoras nos âmbitos teórico-conceitual e/ou teórico-metodológico que passaram pelo GT nessas duas décadas sem, necessariamente, ter mencionado o termo.

A fim de alcançar o objetivo proposto, realizamos uma combinação de técnicas de abordagem quantitativa e qualitativa - coleta de dados, descrição e análise (LOPES, 2010). Com base na Análise de Conteúdo (BARDIN, 1977), estabelecemos três categorias de análise: trajetórias, objetos e concepções.

\section{Sobre o conceito de inovação}

Considerado o primeiro teórico clássico da inovação, Schumpeter (1984) se consagrou pelo conceito de "destruição criativa" como elemento essencial do capitalismo, considerando que este altera a estrutura econômica a partir do contexto interno, pois a sua dinâmica cria e, ao mesmo tempo, destrói, produzindo uma contínua mutação que "incessantemente revoluciona a estrutura econômica a partir de dentro, incessantemente destruindo a velha, incessantemente criando uma nova" (SCHUMPETER, 1984, p. 113). Ou seja, para esse autor, a inovação se relaciona às novas combinações (MARTINS, 2018) e, como bem reforça Mazza $(2013,2014)$ em seus estudos sobre Schumpeter, à introdução do novo se acrescenta a combinação de recursos.

Essa visão é reforçada por Drucker (2003, p. 45), para quem inovar "consiste na busca deliberada e organizada de mudanças e na análise sistemática das oportunidades que tais mudanças podem oferecer para a inovação econômica ou social”. Mudar é uma palavra central

\footnotetext{
${ }^{2}$ Anais da Compós. Disponível em: https://www.compos.org.br/anais_encontros.php. Acesso em: 09 jun. 2019. 120
} 
no contexto da inovação, como bem esclarece Rossetti (2013) em suas pesquisas sobre Comunicação e inovação. Acreditando-se que toda mudança traz o novo, sendo capaz de gerar novos estados, torna-se, como bem ressalta a autora, fundamental para compreendermos o conceito de inovação. No entanto, por ser "um conceito genérico que perpassa várias categorias, ele não pode ser classificado como uma das categorias de inovação" (ROSSETTI, 2013, p. 67) ${ }^{3}$. Isso quer dizer que mudança não se trata de uma das categorias de inovação, mas está na essência de todas elas (MARTINS, 2018). Compreender essa essência da inovação nos ajuda a perceber suas concepções.

Miége (2009a) concebe a inovação como um elemento central para posicionar a técnica e diz que as pesquisas a respeito do tema desenvolvidas no seio das Ciências Humanas e Sociais, inclusive em Ciências da Informação e da Comunicação, têm procurado evidenciar o papel da mediação social. O pesquisador "considera as TIC como uma inovação de ruptura essencial à compreensão do processo de informação/comunicação contemporâneo" (MIÉGE, 2009b, p. 122), processo esse que ele chama de comunicação midiatizada.

Defendemos a existência e relevância de aspectos e dimensões mais sensíveis da inovação no Jornalismo, visto que seus sentidos nos mostram a ocorrência e importância da dimensão sociocultural, manifestada no dia a dia da sociedade e que, como bem ressalta Martins (2018), no Jornalismo, aflora em todos os seus setores, seja na gestão, na formação de equipe, seja nos processos produtivos, nas narrativas e nos produtos.

Vários estudos (ROSSETTI, 2013; BARBOSA, 2014; FONSECA, 2015; GIACOMINI FILHO, 2015; SILVERMAN, 2015; LEONHARDT et al., 2017; MARTINS, 2018) têm nos mostrado que a inovação na Comunicação, especialmente no Jornalismo, pode estar presente nas formas narrativas, nos processos produtivos, nos dispositivos tecnológicos e/ou interativos, na gestão, no perfil das equipes, nas reportagens ou mesmo nas etapas de circulação e consumo das informações. Portanto, são muitas as concepções que podemos atribuir à inovação.

No entanto, a riqueza e complexidade da relação entre inovação e Jornalismo apontam para uma cultura aberta à inovação (SILVERMAN, 2015), cujos impactos estão também na esfera social, uma vez que muda as relações na sociedade. E são justamente esses outros aspectos e/ou sentidos que queremos compreender.

\footnotetext{
${ }^{3}$ Baseada na classificação aristotélica do conceito de mudança, Rosseti (2013) adota oito categorias: inovação substancial, qualitativa, quantitativa, relativa, espacial, temporal, ativa e passiva.
} 


\section{Percurso metodológico}

No percurso metodológico, iremos adotar as abordagens quantitativa e qualitativa de forma complementar, visto que é cada vez mais difícil distinguir os limites exatos entre esses dois tipos de pesquisa (LOPES, 2010). Os estudos quantitativos amparam-se em dados qualitativos, já as investigações qualitativas utilizam-se da quantificação das informações coletadas: após a organização, a tabulação e a quantificação dos materiais, o pesquisador volta para a qualificação dos mesmos. Foram realizadas as seguintes etapas: coleta de dados, descrição e análise, além da pesquisa bibliográfica que aqui é entendida como etapa elementar de qualquer investigação.

A coleta de dados foi dirigida pelo prefixo 'inov', levando-nos a encontrar as seguintes palavras: inovar, inovação, inovações, inovador(a), inovadores(as). A busca, que inicialmente seria feita apenas em títulos, resumos e palavras-chave, foi ampliada para todo o corpo de texto dos trabalhos, pois nos primeiros anos, nem todos os artigos apresentavam resumo e/ou palavras-chave. Todos os artigos foram coletados dos anais eletrônicos da Compós, disponibilizados no site da Associação. Do total de 200 artigos apresentados no GT Estudos de Jornalismo da Compós de 2000 até 2019, 59 foram selecionadas como corpus deste trabalho.

Feito esse primeiro levantamento e seleção, partimos para a descrição e análise dos artigos em si, buscando compreender o contexto em que o termo inovação vem sendo associado ao jornalismo, sobretudo, no que se refere às trajetórias, aos objetos e às concepções de pesquisa. A descrição pode ser entendida como a primeira etapa da análise. Ela é composta pela organização e tabulação dos dados coletados, bem como pela própria descrição das principais características. Já a análise é compreendida como uma segunda etapa, quando os dados empíricos são interpretados e teorizados e, a pesquisa, por sua vez, "atinge a condição própria de cientificidade" (LOPES, 2010, p. 151).

A descrição e a análise foram norteadas por uma tabulação estruturada em: título do artigo, autor(a), coautor(a), instituição, ano de produção, resumo, abordagem e, quando justificado, objetos analisados e dispositivos. Tal sistematização auxiliou na descrição e análise 
dos dados. Desse modo, a descrição e a análise apresentadas a seguir foram realizadas com foco em três categorias, as quais norteiam as reflexões que trazemos para este artigo:

1) trajetória da produção: refere-se à frequência de uso do termo, ao período de publicação do artigo, ao referencial teórico utilizado e à instituição de vinculação dos autores;

2) objetos: diz respeito aos principais eixos de abordagem dos objetos de estudo e objetos empíricos, nesse caso abordando os produtos e/ou organizações jornalísticas mais enfocados nas pesquisas;

3) concepções: relaciona-se aos sentidos de inovação que despontam nas pesquisas.

Destacamos que tanto a coleta de dados, quanto a descrição e a análise apresentadas a seguir se baseiam na Análise de Conteúdo que, para Bardin (1977, p. 38), consiste em "um conjunto de técnicas de análise das comunicações que utiliza procedimentos sistemáticos e objectivos de descrição do conteúdo das mensagens". No entanto, a própria autora diz que "isto não é suficiente para definir a especificidade da análise de conteúdo", pois o seu interesse "não reside na descrição dos conteúdos, mas sim no que estes nos poderão ensinar após serem tratados (por classificação, por exemplo) relativamente a «outras coisas»" (BARDIN, 1977, p. 38).

\section{Trajetória da produção}

Embora nem todos os artigos analisados tratassem de temas, de fato, relacionados à inovação no Jornalismo, percebemos o aumento do uso do termo na última década, sobretudo, em 2010, 2016 e 2018. Do total de dez artigos por ano do GT de Estudos de Jornalismo, destacamos que cinco artigos continham o prefixo "inov" em 2010, seis em 2016 e sete em 2018 (ver gráfico 1). Nesse sentido, destacamos também que na primeira década (2000-2009) houve 22 artigos que usaram o prefixo “inov”. Já na segunda década (2010-2019), esse número saltou para 37. 
Gráfico 1: Quantidade de artigos com o prefixo "inov" apresentados no GT Estudos de Jornalismo da Compós por ano.

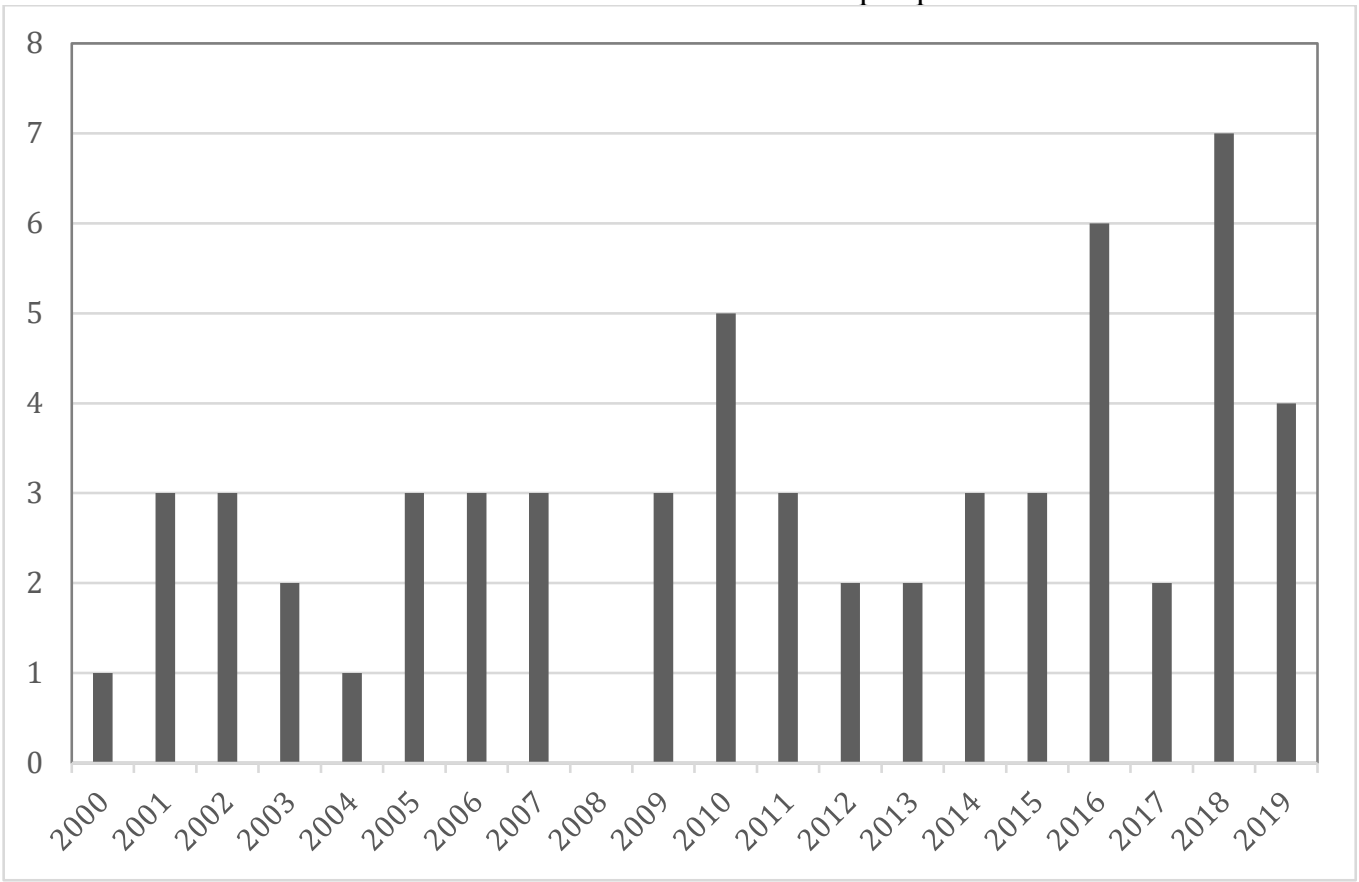

Fonte: Elaboração própria.

Contudo, se formos examinar quantas vezes localizamos o prefixo "inov" em cada um dos trabalhos analisados, o encontramos com maior frequência ${ }^{4}$, apenas em um caso na década de 2000 e seis na década seguinte, 2010. São eles:

a) Um panorama da produção jornalística audiovisual no ciberespaço: as experiências das redes colaborativas. Autoras: Beatriz Becker e Juliana Teixeira. Instituição: UFRJ. Ano: 2009. O prefixo aparece oito vezes;

b) Cinco hipóteses sobre o fotojornalismo em cenários de convergência. Autor: José Afonso da Silva Junior. Instituição: UFPE. Ano: 2011. O prefixo aparece nove vezes; c) Affordances indutoras de inovação no jornalismo móvel de revistas para tablets. Autores: Adalton Fonseca e Suzana Barbosa. Instituição: UFBA. Ano: 2016. O prefixo aparece 50 vezes;

d) A matriz de avaliação e o índice de qualidade como suportes para aferição da qualidade do telejornalismo nas emissoras públicas. Autores: Iluska Coutinho e José

\footnotetext{
${ }^{4}$ Por conta do tamanho do corpus analisado, selecionamos os artigos em que o prefixo "inov" aparece com mais frequência - no caso, a partir de oito vezes, considerando-se que esse foi o número que nos permitiu padronizar a amostragem, uma vez que os demais apresentavam um número muito variado.
} 
Tarcísio Oliveira Filho. Instituição: UFJF e UFMG. Ano: 2016. O prefixo aparece oito vezes;

e) A produção de conhecimento no jornalismo: transformações e renovações do cenário contemporâneo. Autor: Carlos Franciscato. Instituição: UFS. Ano: 2018. O prefixo aparece 35 vezes;

f) Imersividade como estratégia narrativa em podcasts investigativos: pistas para um radiojornalismo transmídia em In the Dark. Autoras: Debora Lopez, Luana Viana e Kamilla Avelar. Instituição: UFOP, CEFET-MG e Universidade FUMEC. Ano: 2018. O prefixo aparece oito vezes;

g) Credibilidade no jornalismo independente em plataformas digitais: uma análise a partir da Agência Pública. Autores: Raphaelle Batista e Edgard Patrício. Instituição: UFC. Ano: 2019. O prefixo aparece 11 vezes.

Destacamos, contudo, dois trabalhos: o artigo de Fonseca e Barbosa (2016) em que o prefixo é usado 50 vezes e o de Franciscato (2018), que o utiliza 35 vezes. Por outro lado, se restringirmos o levantamento apenas ao título ou ao resumo ou às palavras-chave, encontramos apenas três casos, sendo que dois deles também apresentam o prefixo "inov" com oito ou mais vezes, conforme já citado, o primeiro e o terceiro a seguir:

a) Um panorama da produção jornalística audiovisual no ciberespaço: as experiências das redes colaborativas. Autoras: Beatriz Becker e Juliana Teixeira. Instituição: UFRJ. Ano: 2009 (prefixo presente no resumo).

b) Brasil entre as telas e as ruas: produção e consumo das narrativas jornalísticas audiovisuais sobre os protestos nacionais de junho de 2013. Autoras: Beatriz Becker e Mônica Machado. Instituição: UFRJ. Ano: 2014 (prefixo presente no resumo).

c) Affordances indutoras de inovação no jornalismo móvel de revistas para tablets. Autores: Adalton Fonseca e Suzana Barbosa. Instituição: UFBA. Ano: 2016 (prefixo presente no título, no resumo e nas palavras-chave).

Detendo-nos aos oito artigos destacados (BECKER; TEIXEIRA, 2009; SILVA JUNIOR, 2011; BECKER; MACHADO, 2014; COUTINHO; OLIVEIRA FILHO, 2016; FONSECA; BARBOSA, 2016; FRANCISCATO, 2018; LOPEZ; VIANA; AVELAR, 2018; BATISTA; PATRÍCIO, 2019), observamos que tratam de temas relacionados, sobretudo, à contemporaneidade, às redes e/ou plataformas digitais, às transformações do jornalismo em um cenário de convergência, envolvendo as reconfigurações nos processos de produção, circulação e consumo da prática noticiosa. Ao apreendermos os referenciais teóricos desses oito trabalhos, 
percebemos que o conceito de inovação no jornalismo é explanado, de fato, somente nos artigos de Fonseca e Barbosa (2016) e Franciscato (2018).

Fonseca e Barbosa (2016) definem o conceito de inovação como:

[...] um fenômeno de múltiplas dimensões [...] em um determinado contexto, a fim de renovar/criar novos produtos/serviços ou novas formas de produção e consumo (FONSECA, 2015). É preciso destacar que um conjunto de elementos deve estar articulado para o andamento do processo que depende de desenvolvimentos técnicos, legislação, além dos anunciantes, instituições de ensino, profissionais envolvidos, sindicatos, empresas intermediárias, consumidores, entre outros (FONSECA; BARBOSA, 2016, p. 2).

Já para Franciscato (2018), a inovação no jornalismo não deve se restringir apenas à dimensão empresarial-industrial do jornalismo, mas englobar fluxos de inovação que surgem das comunidades sociais e abarcam as organizações. Nesse sentido, o autor considera que "a capacidade inovadora de uma organização jornalística estará atrelada, então, ao perfil dos demais atores econômicos em um espaço social, assim como aos agentes governamentais, escolas de formação e pesquisa e organizações da sociedade civil” (p. 15).

No que se refere às instituições, dentre aquelas que apresentam maior quantidade de artigos relacionados à inovação no jornalismo, destacam-se: a UFRJ com sete trabalhos, a USP e a UFBA com seis papers cada uma, a UFRGS com cinco e a UFS com quatro. Já no que diz respeito aos autores, os que mais apresentaram pesquisas no GT de Estudos de Jornalismo da Compós, que trazem o prefixo “inov" são: Beatriz Becker (UFRJ) e Suzana Barbosa (UFBA) com cinco artigos cada uma, Carlos Franciscato (UFS) com quatro trabalhos.

\section{Objetos analisados}

Dentre os artigos analisados identificamos, tanto pesquisas que buscam discutir e compreender as transformações pelas quais o jornalista e/ou jornalismo (em seu campo profissional e acadêmico) vêm passando nas últimas décadas, quanto investigações que têm como objetos empíricos o jornalismo nas mais distintas plataformas. No que se refere aos objetos de estudo dos trabalhos examinados, percebemos a existência de cinco eixos de abordagem principais ${ }^{5}$ :

1. reconfigurações das narrativas (onze casos);

2. transformações do jornalismo (onze casos);

3. linguagens e formatos (dez casos);

\footnotetext{
${ }^{5}$ Há ainda uma menor quantidade de trabalhos que trata de: modelo de jornalismo; valores jornalísticos; disciplinas e currículos do curso de Jornalismo; qualidade; jornalismo de proximidade. 
4. novas modalidades de jornalismo com foco no digital (nove casos);

5. identidade e mudanças do trabalho do jornalista (cinco casos).

Portanto, percebemos que as inovações no jornalismo têm sido pesquisadas em distintas esferas. Em ambas as décadas em foco é perceptível a necessidade dos pesquisadores em buscar a compreensão referente aos resultados trazidos pela aproximação do público com os conteúdos jornalísticos a partir das tecnologias digitais. Muito do que se fala sobre inovação faz alusão apenas ao desenvolvimento de suportes tecnológicos, no entanto, o objetivo dos trabalhos, em sua maioria, é abordar as questões que perpassam diferentes atores sociais - jornalistas e/ou público, seja por meio das práticas de produção e alterações de rotina, seja através das transformações de narrativas, linguagens e formatos na internet e nas tecnologias digitais.

De 2000 até 2009, observamos um esforço na conceituação de webjornalismo, de base de dados, bem como de análise de casos de jornalismo participativo e de uso de recursos multimidiáticos e interativos nas narrativas. Com o tempo, percebemos que as pesquisas deram cada vez mais espaço para análise de narrativas (transmídia, long form etc.), novos formatos (podcasts) e recursos voltados à sensorialidade e experiência do público (imersividade), buscando entender os aspectos da inovação. De 2010 até 2019, por sua vez, verificamos a dedicação em refletir sobre o uso da base de dados nas narrativas jornalísticas e, mais tarde, do jornalismo guiado por dados; assim como acerca da conceituação de narrativas multimídia, do modelo narrativo de jornalismo digital, do jornalismo long form; das práticas de jornalismo participativo; do uso de site de redes sociais; das transformações das fotografias e dos processos gráficos e editoriais; da evolução do webjornalismo; de novos dispositivos que foram apropriados pelo jornalismo, como os tablets, e seus recursos que permitem maior autonomia ao usuário; e, ainda, dos conceitos teóricos do jornalismo. Há, ainda, a preocupação em definir o conceito de inovação, como vimos em Fonseca e Barbosa (2016) e Franciscato (2018).

Percebemos, assim, um incremento não só na quantidade de artigos que discutem aspectos da inovação no Jornalismo, como também uma expansão dos objetos de estudo de uma década para a outra. Não podemos deixar de destacar o aumento de objetos empíricos digitais (podcasts, revistas e/ou jornais para tablet, portais de notícia etc.) analisados a partir da segunda década em foco, sobretudo, em produtos específicos, em novas funções do jornalista e, principalmente, em novas narrativas e experiências de usuário.

Verificamos que essas pesquisas buscam discutir a inovação no Jornalismo nas mais diversas esferas, tendo como objetos empíricos, principalmente, as tradicionais organizações 
jornalísticas. As empresas noticiosas que mais aparecem como objeto de análise são: Grupo Estado; Grupo Folha; Grupo Globo; The Guardian; The New York Times.

Nesse conjunto de artigos selecionados, observamos que o uso da palavra inovação e seus derivados semânticos ultrapassam o viés tecnológico, a exemplo dos eixos de abordagens relacionadas às narrativas, linguagens e, sobretudo, à identidade e ao trabalho dos jornalistas. Percebemos também a inovação como uma espécie de conceito guarda-chuva, ou seja, um termo que pode abrigar várias práticas, recursos e técnicas.

\section{Concepções da inovação no jornalismo}

Do conjunto de trabalhos analisados, o primeiro artigo a trazer o termo inovação chamase "Atualidade no Jornalismo", do pesquisador Carlos Franciscato (2000). Sua referência ao termo inovação vincula-o ao contexto dos usos tecnológicos e desponta uma dimensão importante, que amplia seus sentidos: a dimensão da temporalidade.

\footnotetext{
Os suportes digitais de informação disponibilizam um volume cada vez maior de conteúdos com variadas marcações de tempo. Pode-se supor, por exemplo, que, para o receptor, as inovações tecnológicas possibilitam novas formas particulares (individuais ou grupais) de construção de temporalidades, pois as mídias tendem a disponibilizar conteúdos que se referem a tempos sociais diversos (como no caso dos jornais on-line, que oferecem tanto a edição diária com notícias do 'dia anterior' quanto 'notícias em tempo real' ou links para edições anteriores), permitindo que os 'leitores' façam seus próprios recortes e relações temporais (FRANCISCATO, 2000, p.17)
}

A dimensão tecnológica e a relação entre inovação e temporalidade são retomadas pelo autor nesse GT em 2004, quando ele traz uma reflexão sobre “o Jornalismo e a Reformulação da Experiência do Tempo nas Sociedades Ocidentais", constatando que os jornais consolidaram sua periodicidade no século XIX a partir das inovações tecnológicas na produção, oferecendo narrativas curtas e efêmeras.

A proposição da categoria 'novidade' para descrever um aspecto específico da temporalidade jornalística pretendeu mostrar que a notícia é indissociável de uma lógica de inovação, originalidade ou renovação que padroniza um modo de reconhecer e definir eventos e os apresentar publicamente por meio do relato jornalístico (FRANCISCATO, 2004, p. 12).

Outros artigos analisados associam o termo inovação à reestruturação do impresso e de suas equipes, a exemplo dos jornais Última Hora e $O$ Globo, exemplificando os eixos transformações no jornalismo e na identidade e mudanças do trabalho do jornalista. Deste último, analisa-se a criação de uma nova editoria (Economia) e a profissionalização de suas 
equipes não apenas como uma forma de competir no mercado, mas, sobretudo "como espaço de 'resistência à ditadura' por parte dos jornalistas" (ABREU, 2001, p.1).

Nas pesquisas apresentadas, há, ainda, referências a elementos de inovação que podem ser usados nas narrativas. No início do século XXI, Luciana Mielniczuk e Marcos Palacios (2001) já destacavam que o fator inovador do link "está relacionado com a forma de organização (léxias) e formatação (interconexão) da informação" (p. 8).

Pensando em recursos (que podem ser associados à dimensão tecnológica), Reis (2002, p. 9) cita como atrativos para a produção jornalística, certas inovações tecnológicas como “jornais coloridos, mais fáceis de manusear, papel de melhor qualidade, melhor qualidade nas transmissões de imagem e som". A relação entre inovação e recursos também é evidenciada no texto de Quadros, Quadros e Masip (2009, p. 11) que, ao analisarem a evolução do webjornalismo, ressaltam que as "inovações também são incorporadas para o usuário/leitor "tocar", adicionar partes, subscrever, enfim: participar".

Nesse sentido, esse papel ativo do usuário como elemento de inovação está presente nos estudos de Fonseca e Barbosa (2016), que a examinam a partir do conceito de affordance, aplicado ao estudo de revistas para tablets no contexto do jornalismo móvel. Os autores acreditam que as affordances inovadoras são "possibilitadas pelos recursos e funcionalidades dos tablets e que também permitem interações inéditas ou renovadas na relação entre usuários e revistas. Entre elas estão: ouvir, assistir, jogar, pesquisar, armazenar" (2016, p.1). O trabalho traz uma discussão sobre a inovação em si, compreendendo-a no contexto transdisciplinar das tradições de investigação. Para eles, esse lugar

\begin{abstract}
exige do pesquisador em ciências sociais um recorte preciso do seu objeto de estudo e um olhar amplo o suficiente para contemplar a transdisciplinaridade do fenômeno (FAGERBERG, 2003). Quando se trata do jornalismo, por exemplo, este conceito pode se referir às mudanças no processo de produção (SILVA, 2013), às alterações nas rotinas e perfis profissionais (PAVLIK, 2008; DAILEY, DEMO E SPILLMAN, 2005), às transformações tecnológicas e ao lançamento de novos produtos jornalísticos (PALACIOS et al. 2015; 2014, BARBOSA, 2014; 2007). É preciso, portanto, estar atento às vertentes tecnológicas, organizacionais e sociais, como aponta Franciscato (2010), na formatação das pesquisas (FONSECA, BARBOSA, 2016, p. 2).
\end{abstract}

Ou seja, no âmbito da inovação no jornalismo, os recursos proporcionam autonomia tanto aos produtores de conteúdo quanto ao público que, por sua vez, inserido na cultura da convergência, assume um papel cada vez mais ativo. E nessa caminhada, o seu olhar, atitude e valores são considerados, sobretudo porque a partir de suas decisões em relação ao conteúdo, como os comentários, mixagens, compartilhamentos, dentre outras ações, os recursos 
inovadores são usados e/ou apropriados de uma forma ou de outra, mudando o percurso de uma narrativa.

Nessa relação entre tecnologias, narrativas e recursos, Barbosa (2006, p. 3) diz que "as bases de dados são vistas como um recurso diferencial e inovador para o jornalismo", cujo emprego "vai gerar inovações quanto aos modos de fazer do jornalismo nas redes digitais" (p.6). Discussão que se fortalece em trabalhos seguintes apresentados pela autora no GT (BARBOSA; TORRES, 2012; BARBOSA; NORMANDE; ALMEIDA, 2014; FONSECA; LIMA; BARBOSA, 2019).

Ao refletir sobre o que chamou de "telejornalismo de qualidade", Becker (2006, p. 2), por sua vez, fala em uma "inovação estética na produção dos programas", considerando como inovadores os programas "universais, experimentais e ousados" (p. 5), destacando os aspectos inovadores das linguagens e formatos jornalísticos e observando, ainda, uma inovação de temas e atores sociais representados por "grupos ou movimentos sociais organizados" (p. 12). Apesar disso, a pesquisadora ressalta que as inovações ainda estão longe do almejado, sendo "apenas um desejo" (p. 2).

Em uma análise sobre como caminha o jornalismo no século XXI, relacionando o digital ao neoanalógico, Laranjeira e Quadros (2007) dizem que “as inovações de um novo meio, como as realizadas pelos jornais na web, também podem ser apropriadas, adaptadas ou renovadas por um antigo meio", incentivando "a participação do público com o uso da cooperação entre duas mídias: digital e impressa" (p.3). Essas mudanças podem ser associadas tanto às transformações como às novas modalidades no jornalismo.

Aliás, quando se trata de mídia digital, as pesquisas sobre inovação no jornalismo são mais recorrentes. Em seus estudos, José Afonso da Silva Junior (2011) traz alguns sentidos do termo inovação, relacionando à multimídia e às práticas inovadoras na articulação narrativa. Para ele, "pensar a inovação de um conjunto de rotinas oferecidas pela convergência é também perceber o ciclo de surgimento, adoção, problematização, crise e abandono, próprio da organização da produção da cultura em moldes capitalistas" (p. 13-14). O autor ressalta que as inovações têm ciclos.

É justamente na busca de novos modelos que o empreendedorismo surge na concepção da inovação. Como ressalta Franciscato (2018, p. 5), atualmente, faz parte do novo perfil profissional "o deslocamento do jornalista para constituir-se como empreendedor autônomo responsável por conceber e conduzir empresas inovadoras de base tecnológica (as startups)". Ao mesmo tempo em que se sustentam na autonomia, ressalta o autor, as startups também 
atuam em parceria com as organizações que "estimulam a criação de divisões ou unidades separadas para que estas assumam o risco e os custos da inovação" (p. 6).

Assumir riscos exige maior flexibilidade e autonomia, inclusive nos aspectos editoriais. No entanto, concordamos com Franciscato (2018) que ressalta a importância de haver integração entre as dimensões tecnológica, organizacional e social para melhor compreendermos a noção de inovação no jornalismo. "Considerar uma inovação no jornalismo não pode ficar restrita apenas à dimensão empresarial-industrial do jornalismo, mas deve englobar fluxos inovativos que brotam das comunidades sociais e atravessam organizações" (p. 14).

É interessante observar que os aspectos de inovação no jornalismo apreendidos nesses artigos vinculam-se: a) Recursos/ Mídias Digitais; b) Reestruturação (redação/trabalho); c) Narrativas; d) Usuário/Público. Percebemos ainda a presença de diferentes sentidos desse conceito, associados à temporalidade, ao âmbito empresarial e, sobretudo, tecnológico, perpassando todos os aspectos acima mapeados.

Desse modo, no GT Estudos de Jornalismo da Compós o conceito de inovação ganha concepções distintas, as quais podem ser compreendidas de forma transdisciplinar. Reconhecemos, contudo, que as pesquisas reforçam os sentidos mais tradicionais de inovação, embora possam despontar também pistas que nos conduzem a percursos cimentados em dimensões mais sensíveis e diferentes, como a compreensão de Hagen $(2006$, p. 9) de que a inovação pode vir da memória, cuja natureza dinâmica, uma vez inserida na comunicação e na cultura, é "capaz de inovar as experiências, o sentido da vida e do mundo". Portanto, um caminho de compreensão que direciona a uma percepção mais ampla da inovação a partir de novas e distintas dimensões.

\section{Considerações finais}

Este artigo teve como objetivo compreender as trajetórias, objetos e concepções atribuídos ao conceito de inovação em pesquisas de Jornalismo, a fim de entender os sentidos da inovação no Jornalismo. Para isso, combinamos técnicas quantitativas e qualitativas (LOPES, 2010), com base no método Análise de Conteúdo (BARDIN, 1977). O corpus é composto por 59 artigos apresentados no GT Estudos de Jornalismo da Compós nos últimos vinte anos (2000 a 2019). A interpretação dos dados foi realizada a partir de três categorias de análise (trajetórias, objetos e concepções) que nos permitiram chegar às conclusões a seguir. 
No que se refere às trajetórias, observamos que houve um aumento do uso do prefixo “inov" na última década, o que pode estar relacionado à popularização das tecnologias digitais e às mudanças de distintas esferas do jornalismo (empresarial, profissional, editorial, do público) causadas por tais tecnologias. Os artigos analisados tratam, sobretudo, de temas referentes à comunicação midiatizada e contemporânea, às redes digitais, às transformações no jornalismo em um cenário de convergência, abarcando alterações nos processos de produção, circulação e consumo do conteúdo jornalístico. Ao olharmos para as trajetórias dessas pesquisas, foi possível verificar também definições do conceito de inovação no jornalismo nos trabalhos de Fonseca e Barbosa (2016) e Franciscato (2018), além de realizarmos um importante mapeamento de pesquisa sobre a temática

Em relação aos objetos de estudo e empíricos, foi possível mapear os principais objetos de estudo: reconfigurações das narrativas; transformações do jornalismo; linguagens e formatos; novas modalidades de jornalismo; identidade e mudanças do trabalho do jornalista. Foi possível perceber também dois momentos principais: na primeira década deste milênio (2000-2009), os estudos se voltavam a compreender, especialmente, o webjornalismo, as bases de dados, o jornalismo participativo e o uso de recursos multimidiáticos e interativos nas narrativas. Na década seguinte (2010-2019), as investigações se dirigiam às bases de dados nas narrativas jornalísticas multimídia, aos sites de redes sociais; à evolução do webjornalismo e novos dispositivos apropriados pelo jornalismo. Além disso, percebemos, ainda, a busca constante por discutir as inovações com base nas mudanças ocorridas sobretudo nas tradicionais organizações jornalísticas. Nesse sentido, a maioria dos objetos empíricos era formada por produtos dos seguintes veículos noticiosos: Grupo Estado, Grupo Folha, Grupo Globo, The Guardian e The New York Times.

Já no que diz respeito às concepções, percebemos que, seguindo uma trajetória de abordagens do termo inovação no âmbito científico, a inovação é recorrentemente associada aos aspectos tecnológicos, sobretudo com a popularização das redes telemáticas e processos digitais. O termo é bastante usado em referência às novidades e transformações, reforçando o pensamento de Rossetti (2013), para quem a concepção de mudança é essencial para a inovação. Nesse sentido, nos artigos analisados, mapeamos os seguintes aspectos vinculados à inovação: recursos/ mídias digitais; reestruturação (redação/trabalho); narrativas; usuário/público e observamos a presença de distintos sentidos de inovação, como: temporalidade, empresarial e tecnológico.

Por conseguinte, destacamos que a maioria desses aspectos tem sido associada à natureza tecnológica do termo inovação no âmbito do jornalismo. No entanto, extrapolando as 132 
fronteiras do GT em foco, autores como Silverman (2015), Leonhardt et al. (2017) e Martins (2018) têm nos mostrado a importância da dimensão sociocultural da inovação, a qual provoca mudanças não apenas na gestão, empresas e produtos, mas também nos processos produtivos e até no perfil da equipe.

Desse modo, entendemos que, no âmbito do Jornalismo, é importante considerarmos dimensões mais sensíveis da inovação, sobretudo, sociais e culturais, considerando-se que o uso e aplicação de aspectos inovadores no jornalismo modificam as empresas, as rotinas e práticas profissionais, os produtos e narrativas jornalísticas, bem como a relação com o público. Uma mudança que altera não somente o fazer jornalístico, mas, especialmente, as relações entre todos os envolvidos.

\section{Referências}

ABREU, A. Jornalistas e editorias de economia. In: ENCONTRO NACIONAL DOS PROGRAMAS DE PÓS-GRADUAÇÃO EM COMUNICAÇÃO, 10., 2001, Brasília. Anais [...]. Brasília: UNB/COMPÓS, 2001.

BARBOSA, S. O que é jornalismo digital em base de dados. In: ENCONTRO NACIONAL DOS PROGRAMAS DE PÓS-GRADUAÇÃO EM COMUNICAÇÃO, 15., 2006, Bauru. Anais [...]. Bauru: UNESP/COMPÓS, 2006.

BARBOSA, S. Agentes de inovação, renovação e de reconfiguração para o jornalismo em tempos de convergência. Revista de Cibercomunicación, Santiago de Compostela, v. 1, n. 1, p. 1-8, 2014.

BARBOSA, S.; NORMANDE, N.; ALMEIDA, Y. Produção horizontal e narrativas verticais: novos padrões para as narrativas jornalísticas. In: ENCONTRO NACIONAL DOS PROGRAMAS DE PÓS-GRADUAÇÃO EM COMUNICAÇÃO, 23., 2014, Belém. Anais [...]. Belém: UFPA/COMPÓS, 2014.

BARBOSA, S.; TORRES, V. Extensões do paradigma JDBD no jornalismo contemporâneo: modos de narrar, formatos e visualização para conteúdos. In: ENCONTRO NACIONAL DOS PROGRAMAS DE PÓS-GRADUAÇÃO EM COMUNICAÇÃO, 21., 2012, Juiz de Fora. Anais [...]. Juiz de Fora: UFJF/COMPÓS, 2012.

BARDIN, L. Análise de conteúdo. Lisboa: Edições 70, 1977.

BATISTA, R.; PATRÍCIO, E. Credibilidade no jornalismo independente em plataformas digitais: uma análise a partir da Agência Pública. In. ENCONTRO NACIONAL DOS PROGRAMAS DE PÓS-GRADUAÇÃO EM COMUNICAÇÃO, 28., 2019, Porto Alegre. Anais [...]. Porto Alegre: PUCRS/COMPÓS, 2019.

BECKER, B. Telejornalismo de qualidade: um conceito em construção. In: ENCONTRO NACIONAL DOS PROGRAMAS DE PÓS-GRADUAÇÃO EM COMUNICAÇÃO, 15., 2006, Bauru. Anais [...]. Bauru: UNESP/COMPÓS, 2006. 
BECKER, B.; TEIXEIRA, J. Um panorama da produção jornalística audiovisual no ciberespaço: as experiências das redes colaborativas. In: ENCONTRO NACIONAL DOS PROGRAMAS DE PÓS-GRADUAÇÃO EM COMUNICAÇÃO, 18., 2009, Belo Horizonte. Anais [...]. Belo Horizonte: PUCMG/COMPÓS, 2009.

BECKER, B.; MACHADO, M. Brasil entre as telas e as ruas: produção e consumo das narrativas jornalísticas audiovisuais sobre os protestos nacionais de junho de 2013. In: ENCONTRO NACIONAL DOS PROGRAMAS DE PÓS-GRADUAÇÃO EM COMUNICAÇÃO, 23., 2014, Belém. Anais... Belém: UFPA/COMPÓS, 2014.

COUTINHO, I.; OLIVEIRA FILHO, J. T. A matriz de avaliação e o índice de qualidade como suportes para aferição da qualidade do telejornalismo nas emissoras públicas. In: ENCONTRO NACIONAL DOS PROGRAMAS DE PÓS-GRADUAÇÃO EM COMUNICAÇÃO, 25., 2016, Goiânia. Anais [...]. Goiânia: UFG/COMPÓS, 2016.

DRUCKER, P. Inovação e espírito empreendedor. São Paulo: Pioneira Thomson, 2003.

FONSECA, A. Convergência e inovação jornalística em revistas para tablets: uma proposta de categorias de análise. In: SIMPÓSIO INTERNACIONAL DE CIBERJORNALISMO, 6. 2015, Campo Grande. Anais [...]. Campo Grande: UFMS/CIBERJOR, 2015.

FONSECA, A.; BARBOSA, S. Affordances indutoras de inovação no jornalismo móvel de revistas para tablets. In: ENCONTRO NACIONAL DOS PROGRAMAS DE PÓSGRADUAÇÃO EM COMUNICAÇÃO, 25., 2016, Goiânia. Anais [...]. Goiânia: UFG/COMPÓS, 2016.

FONSECA, A.; LIMA, L.; BARBOSA, S. Uma proposta de framework teórico para análise da experiência no Jornalismo Imersivo. In: ENCONTRO NACIONAL DOS PROGRAMAS DE PÓS-GRADUAÇÃO EM COMUNICAÇÃO, 28., 2019, Porto Alegre. Anais [...]. Porto Alegre: PUCRS/COMPÓS, 2019.

FRANCISCATO, C. E. A atualidade no jornalismo. In: ENCONTRO NACIONAL DOS PROGRAMAS DE PÓS-GRADUAÇÃO EM COMUNICAÇÃO, 9., 2000, Porto Alegre. Anais [...]. Porto Alegre: UFRGS/COMPÓS, 2000.

FRANCISCATO, C. E. As novas configurações do jornalismo no suporte on-line. In: ENCONTRO NACIONAL DOS PROGRAMAS DE PÓS-GRADUAÇÃO EM COMUNICAÇÃO, 13., 2004, São Bernardo do Campo. Anais [...]. São Bernardo do Campo: COMPÓS, 2004.

FRANCISCATO, C. E. A produção de conhecimento no jornalismo: transformações e renovações do cenário contemporâneo. In: ENCONTRO NACIONAL DOS PROGRAMAS DE PÓS-GRADUAÇÃO EM COMUNICAÇÃO, 27., 2018, Belo Horizonte. Anais [...]. Belo Horizonte: UFMG/COMPÓS, 2018.

GIACOMINI FILHO, G. A responsabilidade social como fator de inovação para a comunicação. Comunicação \& Inovação, São Caetano do Sul, v. 16, n. 31, p. 77-93, maio/ago, 2015. 
HAGEN, S. Jornalismo, mito e linguagem: uma abordagem teórica dos apresentadoresestrela. In: ENCONTRO NACIONAL DOS PROGRAMAS DE PÓS-GRADUAÇÃO EM COMUNICAÇÃO, 15., 2006, Bauru. Anais [...]. Bauru: UNESP/COMPÓS, 2006.

LARANGEIRA, Á.; QUADROS, C. Assim caminha o jornalismo do século XXI: do digital ao neo-analógico. In: ENCONTRO NACIONAL DOS PROGRAMAS DE PÓSGRADUAÇÃO EM COMUNICAÇÃO, 16., 2007, Curitiba. Anais [...]. Curitiba: UTP/COMPÓS, 2007.

LEONHARDT, D. et al. Journalism that stands apart. The report of the 2020 Group. The New York Times, New York, 2017. Disponível em: https://goo.gl/nj6j2r. Acesso em: 13 fev. 2017.

LOPES, M. I. V. Pesquisa em Comunicação. São Paulo: Edições Loyola, 2010.

LOPEZ, D.; VIANA, L.; AVELAR, K. Imersividade como estratégia narrativa em podcasts investigativos: pistas para um radiojornalismo transmídia em In the Dark. In: ENCONTRO NACIONAL DOS PROGRAMAS DE PÓS-GRADUAÇÃO EM COMUNICAÇÃO, 17. 2018, Belo Horizonte. Anais [...]. Belo Horizonte: UFMG/COMPÓS, 2018.

MARTINS, E. Modos e sentidos da inovação no jornalismo. Comunicação \& Inovação, São Caetano do Sul, v. 19, n. 39, p. 35-49, jan-abril, 2018.

MAZZA, C. Capacidades dinâmicas e inovação em serviços: um estudo de caso das práticas de sustentabilidade empresarial do Laboratório Sabin. 2013. Dissertação (Mestrado em Administração) - Faculdade de Economia, Administração, Contabilidade e Ciência da Informação e Documentação, UNB, Brasília, 2013.

MAZZA, C. Afinal, o que é inovação? Portal Educação, São Paulo, 29 abr. 2014. Administração e Gestão. Disponível em: https://bit.ly/38HjUqZ. Acesso em: 10 mar. 2020.

MIÉGE, B. A sociedade tecida pela comunicação: Técnicas da Informação e da Comunicação: entre inovação e enraizamento social. São Paulo: Editora Paulus, 2009a.

MIÉGE, B. Comunicação e tecnologia na sociedade: uma dimensão transversal. [Entrevista concedida a Elizabeth Saad Corrêa. Matrizes, v. 3, n. 1, p. 121-126, ago/dez 2009b.

MIELNICZUK, L.; PALACIOS, M. Considerações para um estudo sobre o formato da notícia na Web: o link como elemento paratextual. In: ENCONTRO NACIONAL DOS PROGRAMAS DE PÓS-GRADUAÇÃO EM COMUNICAÇÃO, 10, 2001, Brasília. Anais [...]. Brasília: UNB/COMPÓS, 2001.

QUADROS, C.; QUADROS, I.; MASIP, P. Webjornalismo: da forma ao sentido. Os casos de Gazeta do Povo e La Vanguardia. In: ENCONTRO NACIONAL DOS PROGRAMAS DE PÓS-GRADUAÇÃO EM COMUNICAÇÃO, 18., 2009, Belo Horizonte. Anais [...]. Belo Horizonte: PUCMG/COMPÓS, 2009. 
REIS, R. Jornalismo: cenários e tendências. In: ENCONTRO NACIONAL DOS PROGRAMAS DE PÓS-GRADUAÇÃO EM COMUNICAÇÃO, 11., 2002, Rio de Janeiro. Anais [...]. Rio de Janeiro: COMPÓS, 2002.

ROSSETTI, R. Categorias de inovação para os estudos em comunicação. Comunicação \& Inovação, Universidade Municipal de São Caetano do Sul, São Caetano do Sul (SP), v. 14, $n^{\circ}$. 27, p. 65-73, jul-dez, 2013.

SCHUMPETER, J. Capitalismo, socialismo e democracia. Rio de Janeiro: Zahar Editores, 1984.

SILVA JÚNIOR, J A. Cinco hipóteses sobre a fotojornalismo em cenários de convergência. In. ENCONTRO NACIONAL DOS PROGRAMAS DE PÓS-GRADUAÇÃO EM COMUNICAÇÃO, 20., 2011, Porto Alegre. Anais[...]. Porto Alegre: UFRGS/COMPÓS, 2011.

SILVERMAN, C. The best practices for innovation within news organizations. 2015. Disponível em: https://goo.gl/SbiVfB. Acesso em: 24 jan. 2017.

\footnotetext{
${ }^{a}$ Docente do Programa de Pós-Graduação em Comunicação, Cultura e Amazônia (PPGCOM) e da Faculdade de Comunicação (Facom) da Universidade Federal do Pará (UFPA). Pós-Doutoranda no Programa de Pós-Graduação em Jornalismo da Universidade Federal de Santa Catarina (UFSC). Doutora em Ciências Socioambientais (NAEA/UFPA) e Mestre em Comunicação Social (UMESP). É coordenadora do Grupo de Pesquisa Inovação e Convergência na Comunicação (InovaCom/UFPA/CNPQ) e membro do Núcleo de Estudos e Produção Hipermídia Aplicados ao Jornalismo (Nephi-Jor/UFSC/CNPQ) e da Rede de Pesquisa Aplicada 'Jornalismo e Tecnologias Digitais' (JorTec/SBPJor).
}

\footnotetext{
${ }^{\mathrm{b}}$ Docente do Programa de Pós-Graduação em Comunicação, Linguagens e Cultura (PPGCLC) e dos cursos de Comunicação Social da Universidade da Amazônia (UNAMA). Pós-doutoranda do Programa de Pós-Graduação em Comunicação, Cultura e Amazônia da Universidade Federal do Pará (PPGCOM/UFPA). Doutora em Comunicação e Informação (PPGCOM/UFRGS) e mestre em Jornalismo (PPGJOR/UFSC). É coordenadora do Grupo de Pesquisa Ubiquidade da Comunicação (UBICOM/UNAMA/CNPQ) e membro dos Grupos de Pesquisa Inovação e Convergência na Comunicação (INOVACOM/UFPA/CNPQ) e Laboratório de Edição, Cultura \& Design (LEAD/UFRGS/CNPQ).
} 